\title{
HapHop-Physio: a computer game to support cognitive therapies in children
}

This article was published in the following Dove Press journal:

Psychology Research and Behavior Management

6 July 2017

Number of times this article has been viewed

\author{
Carolina Rico-Olarte' \\ Diego M López' \\ Santiago Narváez' \\ Charic D Farinango' \\ Peter S Pharow ${ }^{2}$ \\ 'Faculty of Electronics and \\ Telecommunications Engineering, \\ Universidad del Cauca, Telematics \\ Engineering Research Group, Popayán, \\ Colombia; ${ }^{2}$ Fraunhofer Institute of \\ Digital Media and Technology IDMT, \\ Ilmenau, Germany
}

Background: Care and support of children with physical or mental disabilities are accompanied with serious concerns for parents, families, healthcare institutions, schools, and their communities. Recent studies and technological innovations have demonstrated the feasibility of providing therapy and rehabilitation services to children supported by computer games.

Objective: The aim of this paper is to present HapHop-Physio, an innovative computer game that combines exercise with fun and learning, developed to support cognitive therapies in children. Methods: Conventional software engineering methods such as the Scrum methodology, a functionality test and a related usability test, were part of the comprehensive methodology adapted to develop HapHop-Physio.

Results: The game supports visual and auditory attention therapies, as well as visual and auditory memory activities. The game was developed by a multidisciplinary team, which was based on the Hopscotch ${ }^{\circledR}$ platform provided by Fraunhofer Institute for Digital Media Technology IDMT Institute in Germany, and designed in collaboration with a rehabilitation clinic in Colombia. HapHop-Physio was tested and evaluated to probe its functionality and user satisfaction.

Conclusion: The results show the development of an easy-to-use and funny game by a multidisciplinary team using state-of-the-art videogame technologies and software methodologies. Children testing the game concluded that they would like to play again while undergoing rehabilitation therapies.

Keywords: computer game, exer-games, cognitive therapies, rehabilitation

\section{Introduction}

Around $15 \%$ of the world population lives with some form of disability or limitation. Children with disabilities are less likely to attend regular school than non-disabled children and are more likely to be unemployed when they become adults. ${ }^{1}$ Cognitive disabilities are commonly associated with major depression and suicidal behavior. ${ }^{2}$ In Colombia, the Ministry of Health and Social Protection reported that more than 1.2 million citizens are living with some kind of disability, with cognitive disabilities being the most frequent ones present in $25 \%$ of the disabled part of the population. In people with cognitive disabilities, $65 \%$ have trouble thinking and memorizing things, and $35 \%$ have problems related to thinking and communication. ${ }^{3}$

Recent studies and technological innovations have demonstrated the feasibility of providing promising therapy and rehabilitation services for children supported by computer games, especially for treating some chronic diseases like diabetes, asthma or cancer; they are as well used for promoting healthy lifestyles like healthy nutrition and exercise. ${ }^{4}$ These games have high potential to enhance children's motivation for

\footnotetext{
Correspondence: Diego M López

Faculty of Electronics and

Telecommunications Engineering,

Universidad del Cauca, Telematics

Engineering Research Group, Calle 5

4-70, Popayán 190002, Cauca, Colombia

Tel +573015819362

Fax +578209813

Email dmlopez@unicauca.edu.co
} 
the therapy and facilitate their understanding of therapeutic concepts, thereby increasing their impact (compliance and adherence). Moreover, using games that combine exercise with fun (so called exer-games) is a well-acknowledged alternative to fight sedentary effects of passive or screen-based videogames. ${ }^{5}$ Exer-games are in place to provide benefits such as increasing physical activity and impacting psychosocial and cognitive aspects of children, hence improving conditions such as suicidal behavior and major depression. ${ }^{6}$ Consoles like Wii and Xbox equipped with sensors (cameras and motion sensors) are frequently used for therapies that promote physical activity in children with obesity or overweight. ${ }^{7-10}$

Still, real evidence on the impact of exer-games, also called active games, as therapeutic aid for children with cognitive disabilities is scare. ${ }^{11}$ An innovative strategy combining exercise and learning processes has been used for cognitive and physical therapies in the elderly. ${ }^{6}$ However, none of the found approaches in children considers strategies such as 1) combining exercise, learning, and fun (exer-learning games), 2) being developed to individually suit the needs of each child, and 3 ) conducting continuous evaluation and monitoring of the patient (user) in order to know and measure the results of the treatment and suggest changes according to the observed results.

This paper aims to present HapHop-Physio, a computer game created to support cognitive therapies dedicated to children. HapHop-Physio is classified as an exer-learning game and consists of a sensor mat (pad) as the input device and a video game for supporting the rehabilitation of children with intellectual and cognitive disabilities, giving a special focus on memory and concentration therapies. The overall purpose of this adopted technology will be the improvement of the outcome of cognitive rehabilitation in children. However, as a first approach for evaluating HapHop-Physio with children, we present the results of the measurement of the satisfaction level achieved with the game: whether the children could be able to play with the game, undergo the therapies, and have fun while playing it.

The remainder of this paper is organized as follows: in the Materials and methods section, we present the Hopscotch $^{\circledR}$ platform on which the HapHop-Physio solution was based on along with the methodology and the specifications used for developing the game and evaluating the satisfaction of children. In the System developing and prototyping section, we explain in detail the structure of the game based on its therapeutic purpose with some gamification elements. In the Game evaluation section, we present the results of the evaluation process with children. Finally, we present the Discussion and Conclusion sections of this paper.

\section{Methods}

In order to establish a well-designed research and development process, a set of methods borrowed from the software engineering discipline has been selected and grouped in a five-fold process (Figure 1). The "Engineering Research Methodology" was adapted towards meeting the clinical and developmental goals. ${ }^{12}$

The first stage of the methodology identification section was a state-of-the-art analysis of existing solutions. As for the second stage, HapHop-Physio was based on the Hopscotch ${ }^{\circledR}$ platform developed by Fraunhofer Institute for Digital Media Technology IDMT in Germany. The platform is based on the popular children's game "hopscotch". ${ }^{6}$ The interaction between the user and the platform is done through an electronic sensor mat (pad). The arrangement of the frames is similar to a T9 keyboard (Figure 2).

The Hopscotch ${ }^{\circledR}$ software component was developed using Unity3D, a platform for creating video games and interactive experiences; ${ }^{13}$ the common characteristic in video games is the ability of the player to interact with a virtual environment, generally through an artifact (e.g., joystick, touch screen control or, in this particular case, the mat); the environment reacts and responds to orders received directly by the player, and it sends new information enabling the users to interact with it. ${ }^{14}$ Hopscotch $^{\circledR}$ strategy is based on the separation of hardware (the mat), software (algorithms), and content (questions, images). Using this strategy, Fraunhofer IDMT has developed several mini-games in a few pre-defined topics (mathematics, languages, and natural sciences); they all require direct interaction between the user and the video

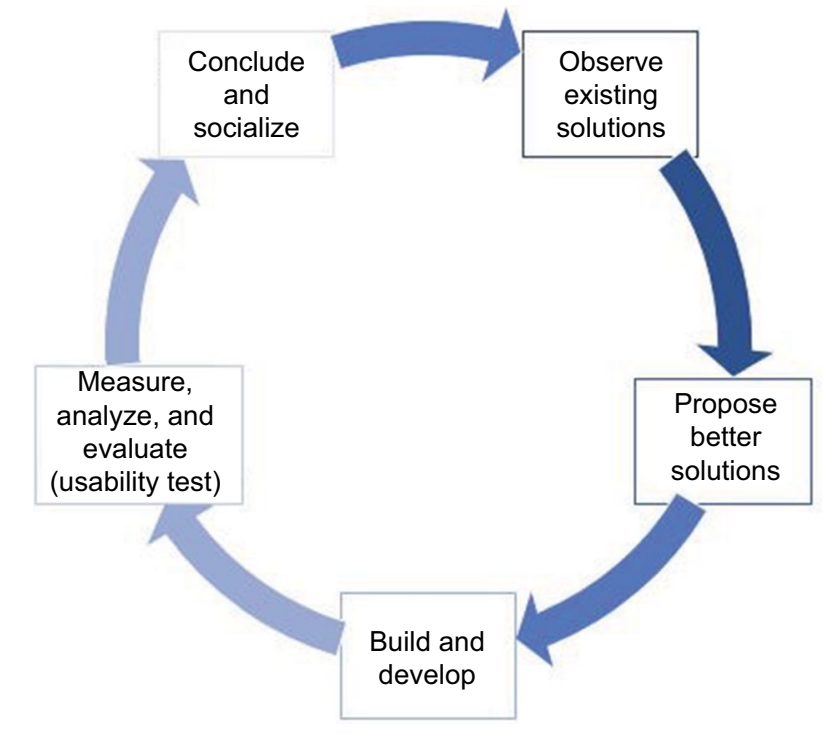

Figure I Stages from adapted methodology. 


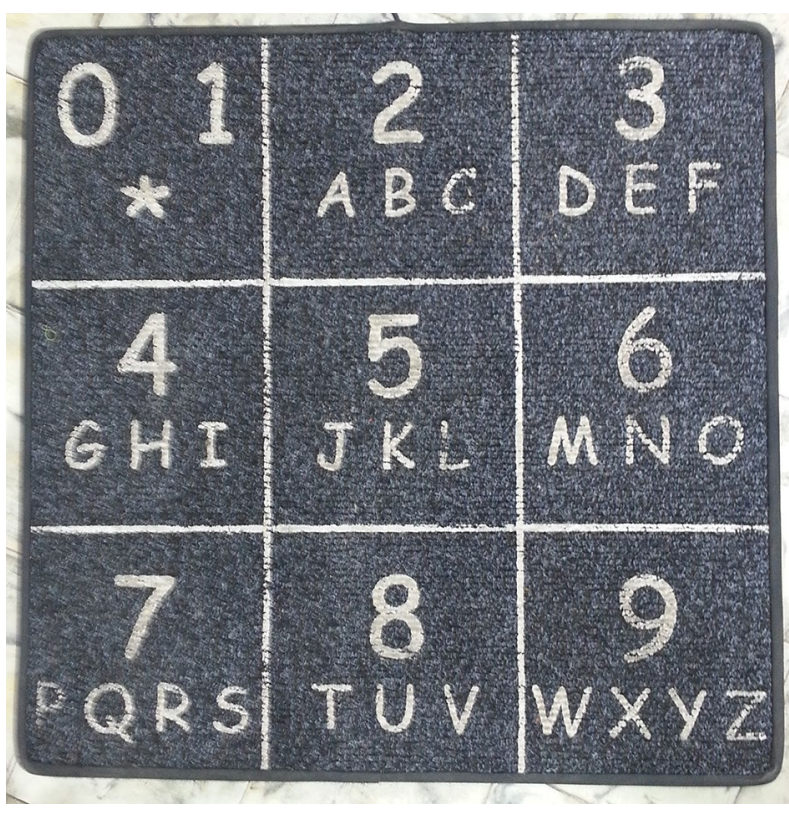

Figure 2 Hopscotch ${ }^{\circledR}$ mat.

game through the mat. Since HapHop-Physio was based on $\operatorname{Hopscotch}^{\circledR}$, its characteristics were taken as:

1. The Model View Controller, an architectural pattern intended to separate the data from the business logic and the user interface of a software product, ${ }^{15}$ was followed to develop the game.

2. A similar set-up to the Hopscotch ${ }^{\circledR}$ mat was used for the interaction between the user and the game. However, it was necessary to perform some modifications to hardware and software, such as adding the letter " $\tilde{n}$ ", an additional physical button, and a mat built with lighter materials for easier transportation.

3. Unity3D development environment for the HapHopPhysio software component was used.

The well-established Scrum approach, an agile framework of iterative and incremental software development, was used as the main software development method ${ }^{16}$ to meet the third stage from the adapted methodology. During each iteration of the Scrum method or Work Sprint (whose length may vary), an update or even upgrade of the operating software was created; the product development process was decomposed resulting in a list of specific features and prioritized objectives. Applying this methodology, the research group performed meetings before and after each particular iteration to plan and evaluate the progress of the project; the process between the meetings was based on a continuous improvement model regarding the developed software. For each weekly deliverable, the speech pathologist evaluated the updated elements of the game against its clinical goal by providing feedback and new requirements to the development engineers until completion of a functional prototype. Concerning clinical aspects, the developmental models based on the cognitive structure of the children and its association with brain development ${ }^{17}$ were used in order to design the structure and content for the video game.

For information capturing of requirements and usage context, the interview method was employed. Based on weekly meetings with cognitive rehabilitation experts, and especially with a speech pathologist responsible for directing the cognitive therapy program for children with identified learning problems in a local rehabilitation clinic in the city, the content of HapHop-Physio was eventually defined.

\section{Testing and evaluation methods}

Continuing with the fourth stage, the present study's design was reviewed and approved by the Ethical Review Board of University of Cauca, Colombia (approval 2016/02/22) prior to recruitment and data collection. In addition, parents or legal guardians of children participating in the testing and evaluation phases signed a written informed consent. The informed consent contained the aims, methods, sources of funding, any possible conflicts of interest, institutional affiliations of the researchers, and the anticipated benefits and potential risks; it followed the ethical standards provided by the Institutional Ethical Review Board, which is consistent with the Helsinki Declaration of 1975, as revised in 2000.

The session for testing the functionality of HapHopPhysio was performed once the first prototype of the product was completed; the test was performed during an event held on September 24, 2015, in a major shopping mall of the city. The developed prototype already had all basic features of the final product, with the exception of the Visual Attention module. Five children with learning deficits, aged between six and 10 years, became part of the testing session. Each child used HapHop-Physio for an average of 30 minutes, performing a series of activities guided by a speech pathologist who had previously been trained in the use of the tool. During each session, the research group observed the way each participant interacted with the product, and at the end of the test, each child was asked about his or her experience with the game.

After the testing session and after performing some necessary adjustments to the game, a second prototype of HapHop-Physio was evaluated in a clinical environment. The evaluation consisted of the qualitative measurement of how funny the game appeared to the children. Fun in general can 
be considered as the denominated "satisfaction". The "Fun Toolkit" method was thus used to measure the fun experienced by children when using the product. The "fun" part of this method has three dimensions: expectations, engagement, and endurability. ${ }^{18}$

The first dimension was measured using Smiley-o-meter (Figure 3). In order to adequately measure the expectation dimension, it was necessary to apply this instrument before and after the child had interacted with the game. The engagement dimension was measured through video recording, identifying the way the children interacted with the product. It appeared to be important to identify signs of fun to determine whether the child had a positive or negative experience.

For the endurability dimension, the "Again-Again Table" was used to measure the desire of the children to repeat an activity they enjoyed. This table consists of four columns: from left to right, first column recorded the related activities followed by the options Yes, Maybe, and No. The table was filled applying the research question: "Would you like to do it again?" Figure 4 shows a part of the table used for the evaluation.

In order to determine how funny the game was to a child, the following evaluation steps were performed:

1. Smiley-o-meter was applied after the child had seen a promotional video about the game itself(Question 1-Q1).

2. The child started interacting with the game for a session lasting about 20 minutes.

3. As soon as the session ended, the child was asked once again to complete Smiley-o-meter (Question 2-Q2).

4. Finally, the child was asked to fill the "Again-Again Table" as it was introduced before.

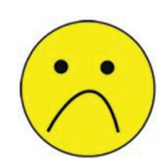

Awful

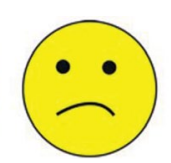

Not very good

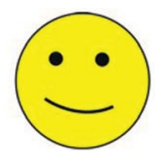

Good

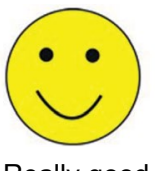

Really good

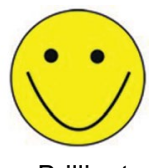

Brilliant

Figure 3 Smiley-o-meter.

Eventually 10 children, aged between five and 16 years, were the subjects of the evaluation. It was performed in a physiotherapy clinic in the city of Popayan. Most of the children were suffering from cognitive disabilities like Down syndrome, attention-deficit hyperactivity disorder (ADHD), and memory deficits. The participants were carefully chosen by the speech pathologist of the clinic responsible for directing the cognitive therapy program.

\section{System development and prototyping}

Bearing in mind Hopscotch ${ }^{\circledR}$ as the application and technology basis as well as the recommendations of the experts, four general modules in the game were defined as the basic structure of HapHop-Physio: Auditory Verbal Memory (AVM), Visual Memory (VM), Visual Attention (VA), and Auditory Attention (AA). Each module has a series of mini-games focusing on the same area.

1. First of all, the main objective of the AVM module is considered to be the enhancement of the ability to recognize and memorize different sounds, such as phonemes, syllables, words, and musical instruments. The patient must fulfill that task to recognize the sound through the dictation of phonemes and syllables. In the case of words and musical instruments, the sequences can vary between one and 12 elements.

2. The VM as the second module is related to the preservation of certain features of our senses associated with the visual experience. ${ }^{19}$ The main objective of this module is to increase the memory capacity of children using different sequences of images and text, managing to reduce learning difficulties.

3. Third, the VA module represents with the ability to perceive and focus on a specific visual stimulus in the presence of distracting images. ${ }^{19}$ Thus, seeking for the child to enhance the ability to separate relevant information from irrelevant, a player can be asked to indicate how many items have a certain image or select certain elements from the image.

Which games would you like to play again?

\begin{tabular}{|l|l|l|l|}
\hline & Yes & Maybe & No \\
\hline
\end{tabular}

Figure 4 Again-Again Table. 
4. Finally, the AA module represents the ability to perceive and focus on a particular sound in the presence of other distracting sounds. ${ }^{19}$ The aim of this module is similar to the previous one; however, it addresses sounds instead of images.

The HapHop-Physio mini-games are classified into four types according to their content: selection games, writing games, reaction games, and repeating sequences games. A particular game belongs to the first category in case the player must select the right response from a variety of options. In the case of writing games, the player must write the correct answer by using the mat. In the reaction games, the player must perform an action as a response to a stimulus. Finally, in the repeating sequences games, the player must memorize and repeat the sequence played in the same order.
The aforementioned four different game types are included in the structure with regard to each of the modules (Figure 5).

The main menu, the chosen character, and the four main modules are displayed as the first scene of the developed game (Figure 6).

Examples of two of the mini-games included in the product are shown in Figures 7 and 8.

The first mini-game is called "Words Sequence" and belongs to the AVM module. The second one is "Images Sequence" belonging to the VM module.

Being fun is one of the main features of a game. ${ }^{20} \mathrm{It}$ allows to capture the attention of the player and to maintain the motivation; given that the interaction with the game is based on reacting to the information available through the mat, HapHop-Physio is an innovative technology that

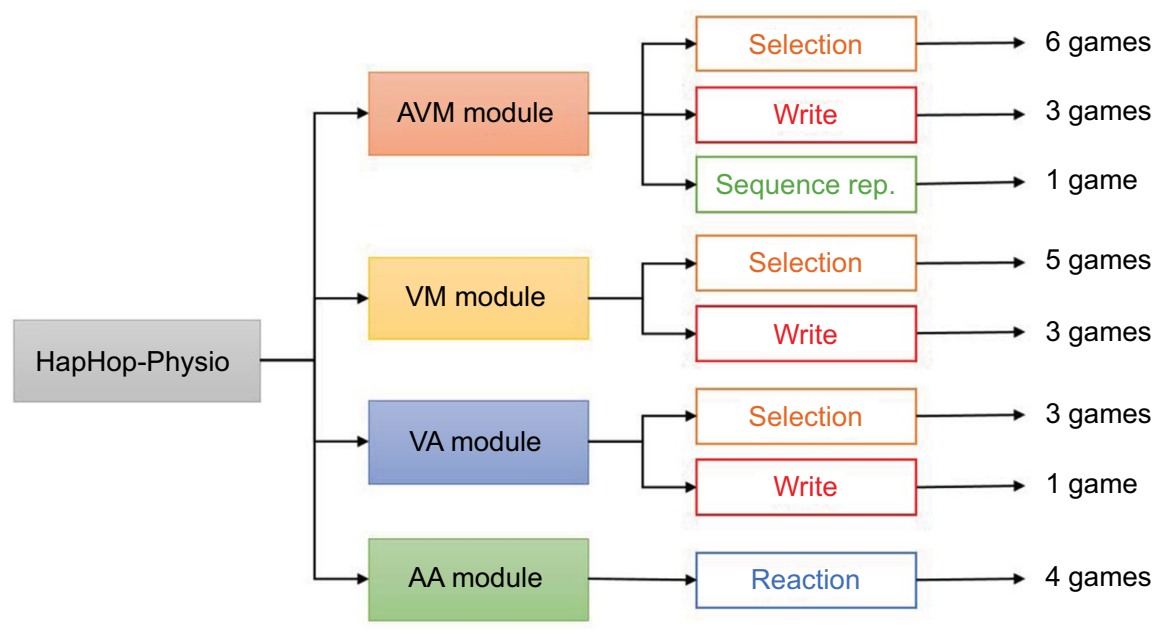

Figure 5 HapHop-Physio structure.

Abbreviations: AVM, Auditory Verbal Memory; VM, Visual Memory; VA, Visual Attention; AA, Auditory Attention.

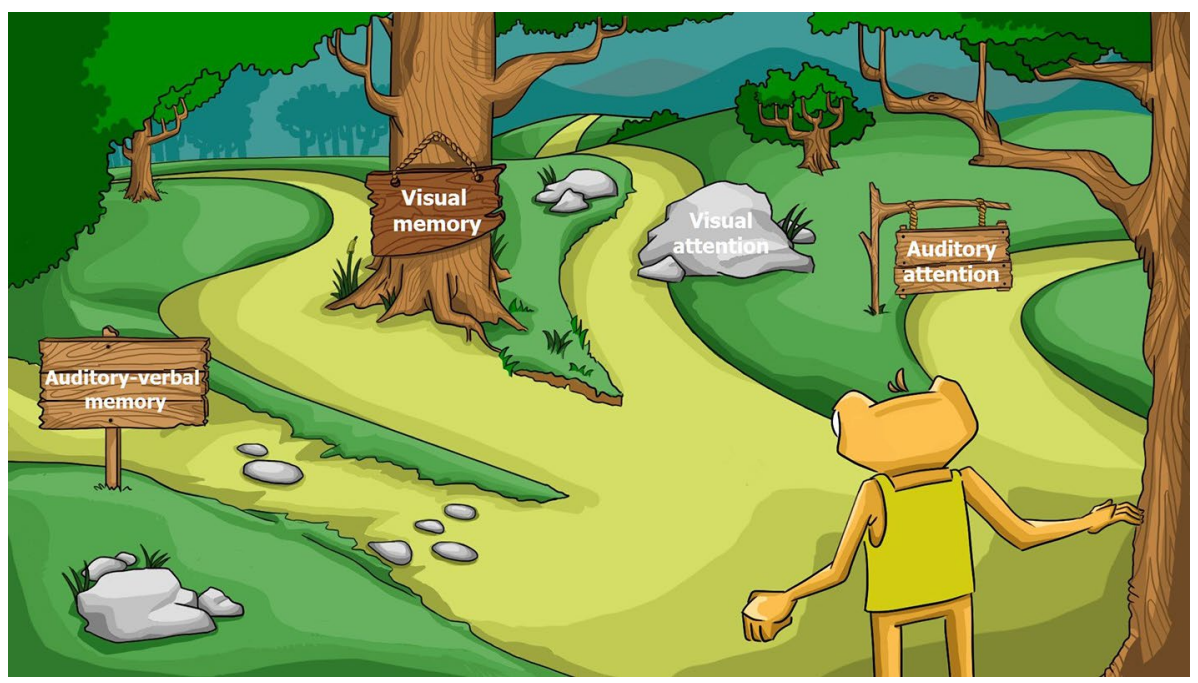

Figure 6 Main menu of the game (translated from the Spanish version of the game). 


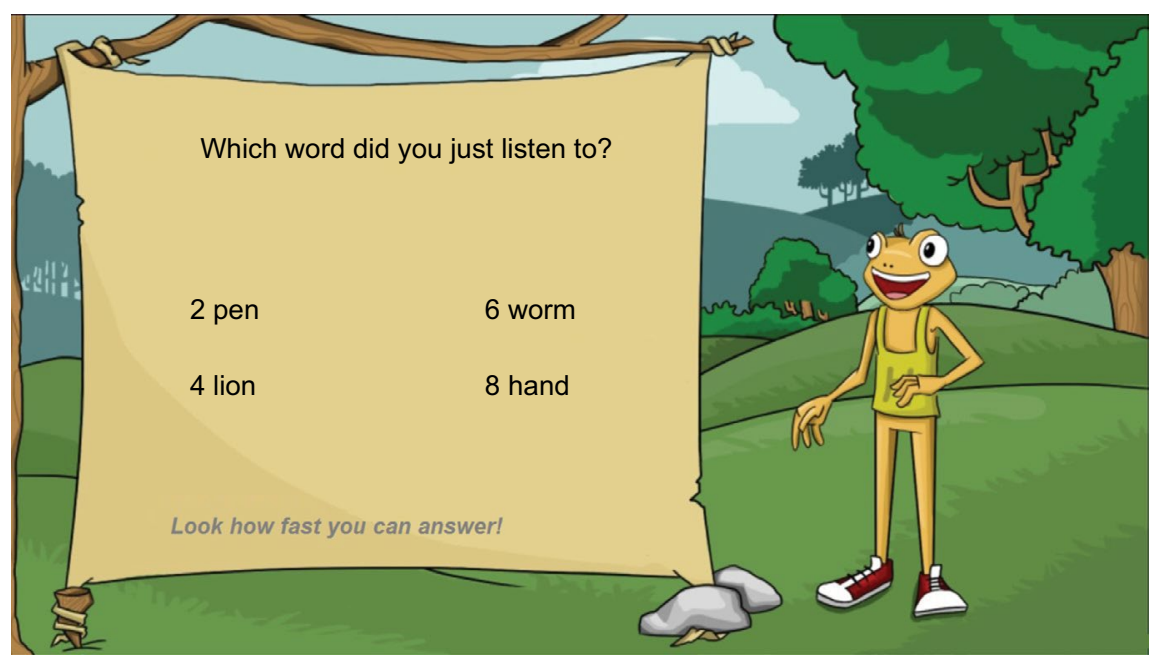

Figure 7 "Words Sequence" mini-game (translated from the Spanish version of the game).

A

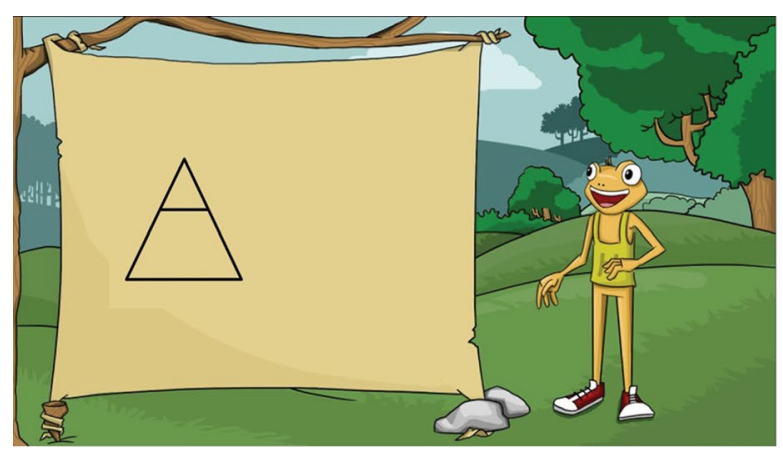

B

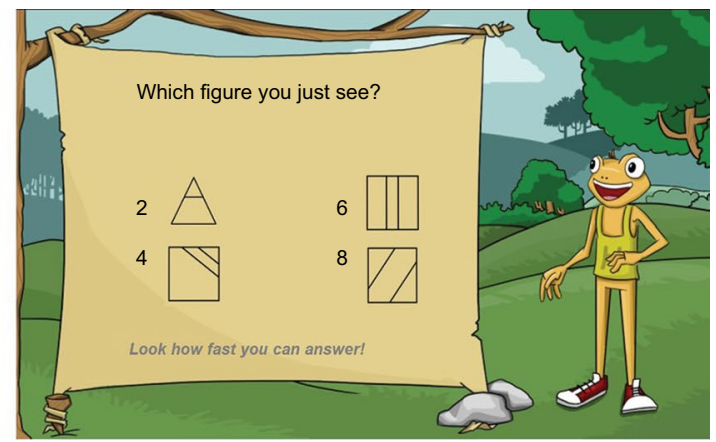

Figure 8 "Images sequence" mini-game. (A) Sequence of images is shown to the player. (B) The player must select the image he/she just saw (translated from the Spanish version of the game).

stimulates the experience of children through physical activity. A main character for the game was created to give it some identity. Taking into account the target audience of the game, children between six and 14 years with learning disabilities and the usage environment of the product as Colombia, a frog, were chosen. A story around the character and theme of the game (memory and attention) were created. The frog has lost its memory, is single, and does not know where its family is; the player must help the frog in remembering its past through a series of tests or mini-games by collecting items to "unblock" a memory flash card.

As mentioned, HapHop-Physio was developed following the main features of Hopscotch ${ }^{\circledR}$ through the Scrum methodology along with gamification elements, considering its final purpose as a rehabilitation game for children with learning disabilities. The first prototype was tested in a non-clinical environment probing its functionality on the software level, and the second HapHop-Physio prototype was evaluated in a clinical environment to probe user satisfaction (children's fun).

\section{Game evaluation}

\section{Testing the first prototype}

A quantitative test was performed with the speech pathologist whose task was to guide the testing sessions. The System Usability Scale (SUS) was used to determine functionality of the game. SUS is a 10-item questionnaire with a Likert scale from 1 to 5 . To calculate the score obtained by applying SUS, the following steps were followed: ${ }^{21}$

1. Odd questions scores $(1,3,5,7$, and 9$)$ must be subtracted from 1.

2. Pair questions scores $(2,4,6,8$, and 10) must be subtracted from 5 and the result is to be multiplied by -1 .

3. Finally, the total scores are summed and the result is multiplied by 2.5 to obtain an evaluation scale from 0 to 100 .

After applying the previous steps for the quantitative test of the product in SUS, the score we obtained was 87.5.

\section{Evaluation of the second prototype}

After the initial testing session, an evaluation of the game was performed in a clinical setting. The results of the satisfaction 
Table I Results from the Fun Toolkit

\begin{tabular}{|c|c|c|c|c|c|c|c|c|}
\hline \multirow[t]{2}{*}{ Item } & \multirow[t]{2}{*}{ Sex } & \multirow[t]{2}{*}{ Age } & \multicolumn{2}{|c|}{ Expectation } & \multicolumn{4}{|l|}{ Endurability } \\
\hline & & & QI & Q2 & $\begin{array}{l}\text { Auditory } \\
\text { Verbal Memory }\end{array}$ & $\begin{array}{l}\text { Visual } \\
\text { Memory }\end{array}$ & $\begin{array}{l}\text { Visual } \\
\text { Attention }\end{array}$ & $\begin{array}{l}\text { Auditory } \\
\text { Attention }\end{array}$ \\
\hline I & $\mathrm{F}$ & 12 & 5 & 5 & Yes & Yes & Yes & Yes \\
\hline 2 & $M$ & 6 & 5 & 5 & - & - & - & - \\
\hline 3 & $M$ & 16 & 3 & 3 & No & Maybe & Maybe & Yes \\
\hline 4 & $M$ & 13 & 5 & 5 & Yes & Yes & Yes & Yes \\
\hline 5 & $M$ & 5 & 5 & 5 & Yes & Yes & Yes & Yes \\
\hline 6 & $M$ & 10 & 5 & 4 & Yes & Yes & Yes & Yes \\
\hline 7 & $M$ & 9 & 5 & 5 & No & Yes & Yes & Yes \\
\hline 8 & $M$ & 11 & 5 & 5 & Yes & Yes & Yes & Yes \\
\hline 9 & $M$ & 10 & 5 & 5 & Yes & Yes & Yes & Yes \\
\hline 10 & $M$ & 8 & 5 & 5 & Yes & Yes & - & - \\
\hline Mode & $M$ & 10 & $5(90 \%)$ & $5(80 \%)$ & Yes (70\%) & Yes (80\%) & Yes (70\%) & Yes (80\%) \\
\hline
\end{tabular}

Abbreviations: F, female; $M$, male.

evaluation of HapHop-Physio are summarized in Table 1. The expectation dimension (Smiley-o-meter) was measured quantitatively from 1 to 5 , with 1 being awful and 5 being brilliant.

\section{Discussion}

In relation to SUS, an expert sets out the best way to interpret the SUS results. ${ }^{22}$ According to this expert, any system with a score higher than 80.3 in the scale belongs to the $10 \%$ of the best rated systems. In this study, a score of 87.5 was obtained, which would position HapHop-Physio as a good rated system according to its functionality as an exer-learning game with rehabilitation purposes. Other researches have evaluated exer-games in terms of improving the physical activity in kids ${ }^{8,10}$ however, none of them reported evaluation results on the functionality of the tool or its usability for the final users.

Regarding the results obtained from the Fun Toolkit, the expectation dimension started with $90 \%$ of the cases rating the game as "Brilliant", and the qualification remains in $88 \%$ of the cases after the second question. The endurability dimension was measured according to the four modules of the game; between $70 \%$ and $80 \%$ of the children assured that they would like to play the games once again. In just one case, the kid did not answer the question from the endurability dimensions due to difficulties related with his disability.

From the overall evaluation, all the kids liked the game and had fun playing it. In general, none of them showed signs of boredom and instead they wanted to keep on playing once the session was completed. Children also seemed to be interested in the story behind the game, which motivated them to win the unlocking elements for the memories of the main character of the story. Regarding the interaction between the player and HapHop-Physio, we observed that the designed control mat of the game should be pretty resistant, because children were rude with the mat.

Until now, despite the positive results from the testing and evaluation sessions, it is important to conduct a formal case study that could bring up some conclusions regarding the potential therapeutic benefits in the health of children. This case study should be conducted with specialists in charge of the children following a validated instrument to measure the progress and improvement of the children in the therapies.

Evaluation of user satisfaction in children is considered a challenging task, especially in the group of children with disabilities. Future work will thus include the definition of instruments to provide a more objective evaluation than the existing qualitative questionnaires as presented in this paper. Some alternatives are foreseen as using psychophysiology sensors like EEG, EMG, and ECG in order to support the process.

\section{Limitations and shortcomings}

Despite the good results obtained in the evaluation of functionality and user satisfaction (children's fun), the limitations presented in this study are related to the following:

1. The number of participants in each test

2. The feasibility of the study in clinical terms since a study with a broader and deeper design and a longer period of application is required

3. The difficulty for some children to fill up or answer questions about their feelings and emotions

4. Lack of adaptation of the tests according to the cognitive disability of the children (e.g., Down syndrome, Autism Spectrum Disorder, ADHD)

5. The subjectivity in the responses provided by the children in the test, as these are biased by the knowledge of the children about themselves and their need for adult approval 
The final part of limitation described is part of a group of gaps taken into account to develop a future work around the measurement in a more objective way of the experience that the children with cognitive disabilities have around the interaction with the developed game.

\section{Conclusion}

HapHop-Physio is an exer-learning game developed according to the specifications from experts in the cognitive therapy area, meeting the rehabilitation needs of children with learning disabilities. HapHop-Physio is a usable and functional game that children with learning disabilities can use it in an easy way. The children expressed their desire to play again with the game and as they did it the first time, they had fun and enjoyed it, allowing us to confirm that due to the use of gamification elements as the main character and its story, the satisfaction evaluation was successful. In consequence, we consider the game as a good start for further clinical assessment of the game in order to verify the purpose for which the project is being built on: supporting cognitive therapies in children with cognitive disabilities.

\section{Acknowledgments}

The authors would like to thank Universidad del Cauca, the VRI project number 4441, Núcleos de Innovación project for financially supporting this applied research, and Fisiocenter, the rehabilitation clinic, particularly Dr. Nathalia Narvaez-Muñoz, Luz A Tovar-Ruíz, and Ana L Pardo for their support and kind cooperation during the course of this project and beyond.

\section{Disclosure}

The authors report no conflicts of interest in this work.

\section{References}

1. WHO. World report on disability. Available from: http://www.who.int/ disabilities/world_report/2011/en/. Accessed December 20, 2016.

2. Gonda X, Pompili M, Serafini G, Carvalho AF, Rihmer Z, Dome P. The role of cognitive dysfunction in the symptoms and remission from depression. Ann Gen Psychiatry. 2015;14.

3. Ministerio de Salud y Protección Social. Registro para la localización y caracterización de personas con discapacidad - RLCPD. Available from: https://www.minsalud.gov.co/proteccionsocial/promocion-social/ Discapacidad/Paginas/registro-localizacion.aspx. Published 2016. Accessed October 31, 2016.
4. Brezinka V. Computer games supporting cognitive behaviour therapy in children. Clin Child Psychol Psychiatry. 2014;19(1):100-110.

5. Saunders TJ, Chaput JP, Tremblay MS. Sedentary behaviour as an emerging risk factor for cardiometabolic diseases in children and youth. Can J Diabetes. 2014;38(1):53-61.

6. Lucht M, Heidig S. Applying HOPSCOTCH as an exer-learning game in English lessons: two exploratory studies. Educ Technol Res Dev. 2013;61(5):767-792.

7. Comité Intersectorial de Seguridad Alimentaria y Nutricional del Cauca. Plan de Seguridad Alimentaria Y Nutricional Para El Departamento Del Cauca; 2009.

8. Cebolla i Martí A, Álvarez-Pitti JC, Guixeres Provinciale J, Lisón JF, Baños Rivera R. Alternative options for prescribing physical activity among obese children and adolescents: brisk walking supported by an exergaming platform. Nutr Hosp. 2014;31(2):841-848.

9. Flynn RM, Richert RA, Staiano AE, Wartella E, Calvert SL. Effects of exergame play on EF in children and adolescents at a summer camp for low income youth. J Educ Develop Psychol. 2014;4(1): 209-225.

10. Lamboglia CM, da Silva VT, de Vasconcelos Filho JE, et al. Exergaming as a strategic tool in the fight against childhood obesity: a systematic review. J Obes. 2013;2013:438364.

11. Pirovano M. The design of exergaming systems for autonomous rehabilitation. Available from: https://www.politesi.polimi.it/handle/10589/108826. Published March 24, 2015. Accessed December 21, 2016.

12. Thiel DV. Research Methods for Engineers. Griffith University, Nathan, QLD, Australia: Cambridge University Press; 2014.

13. Unity. Game engine Unity. Available from: https://unity3d.com. Accessed December 11, 2016.

14. Caroux L, Isbister K, Le Bigot L, Vibert N. Player-video game interaction: a systematic review of current concepts. Comput Hum Behav. 2015;48:366-381.

15. Leff A, Rayfield JT. Web-application development using the model/view/ controller design pattern. In: EDOC '01 Proceedings of the 5th IEEE International Conference on Enterprise Distributed Object Computing. Washington, DC, USA: IEEE Computer Society; 2001:118. Available from: http://dl.acm.org/citation.cfm?id=645344.650161. Accessed October 31, 2016.

16. Schwaber K, Sutherland J. The scrum guide. The definitive guide to scrum: the rules of the game. Scrum.Org; 2013.

17. Holmes-Bernstein J. Developmental neuropsychological assessment. Pediatr Neuropsychol Res Theory Pract. 2000:405-438.

18. Read J, Macfarlane S. Endurability, engagement and expectations: measuring children's fun. In: Interaction Design and Children, Shaker Publishing. Shaker Publishing; 2002:1-23.

19. Rosselli M, Matute E, Ardila A. Neuropsicología del desarrollo infantil. Editorial El Manual Moderno; 2010.

20. Johnson WL, Vilhjalmsson H, Marsella S. Serious games for language learning: how much game, how much AI? In: Proceedings of the 2005 Conference on Artificial Intelligence in Education: Supporting Learning Through Intelligent and Socially Informed Technology. Amsterdam, The Netherlands: IOS Press; 2005:306-313. Available from: http:// dl.acm.org/citation.cfm?id=1562524.1562569. Accessed October 31, 2016.

21. Brooke J. SUS-A quick and dirty usability scale. Usability Eval Ind. 1996;189(194):4-7.

22. Sauro J. A practical guide to the system usability scale: background, benchmarks \& best practices. USA: Measuring Usability LLC; 2011. 
Psychology Research and Behavior Management is an international, peerreviewed, open access journal focusing on the science of psychology and its application in behavior management to develop improved outcomes in the clinical, educational, sports and business arenas. Specific topics covered in the journal include: Neuroscience, memory and decision making; Behavior modification and management; Clinical applications; Business and sports performance management; Social and developmental studies; Animal studies. The manuscript management system is completely online and includes a very quick and fair peer-review system, which is all easy to use. Visit http://www. dovepress.com/testimonials.php to read real quotes from published authors.

Submit your manuscript here: https://www.dovepress.com/psychology-research-and-behavior-management-journal 